\title{
Os tensionamentos entre o global e o local: as ações de responsabilidade socioambiental da Aracruz Celulose e Papel
}

\author{
The tension between the global and the local: social-environmental responsibility \\ actions of Aracruz Celulose e Papel
}

\section{Les tensions entre le global e le local: les actions de reponsabilité environnementale Aracruz Celulose e Papel}

Los tensionamientos entre lo global y lo local: Las acciones de responsabilidad socioambiental de Aracruz Celulose e Papel

\author{
João Vicente R. B. Costa Lima \\ (jvcostalima@gmail.com) \\ François Gavard \\ (francois_gavard@yahoo.com.br)
}

Recebido em 30/03/2012; revisado e aprovado em 29/07/2012; aceito em 02/03/2013

\begin{abstract}
Resumo: O presente artigo analisa as ações de responsabilidade socioambiental da Aracruz Celulose e Papel, refletindo (I) se, genericamente, ocorre uma rearticulação do campo econômico com base em novos valores socioambientais que redimensionariam as instituições do Estado, da Sociedade e do Mercado e (II) se, mais especificamente, são produzidos efeitos mais sustentáveis no nível de interação entre o cidadão-consumidor e o mercado. Ao fundo, discutem-se as (in)congruências entre o global e o local.

Palavras-chave: Responsabilidade Socioambiental. Desenvolvimento. Racionalidade empresarial.

Abstract: The present article analyses the social-environmental responsibility actions of Aracruz Celulose e Papel reflecting (I) if generically, a re-articulation of the economic field occurs based on new social-environmental values that would redimension the State, the Society and the Market institutions and (II) if, more specifically, more sustainable effects are produced in the level of interaction between the consumer citizen and the market. In substance, the (in)consistency between global and local development is discussed.

Key words: Social-environmental responsibility. Development. Business rationality.

Résumé: Cet article analyse les actions de responsabilité socioambientale d'Aracruz Cellulose et Papier ayant le but de réflechir, I) tout d'abord, s'il s'est produit, de façon génerique, une réarticulation du champ économique basée sur de nouvelles valeurs socioambientales qui changeraient les institutions de l'État, de la Société et du Marché, et II) aussi, plus spécifiquement, si sont produits des effets plus durables au niveau de l'interaction entre le citoyenconsommateur et le marché. Dans ce contexte sont discutés (in) congruences entre le global et le local développement.

Mots-clés: Responsabilité socioambientale. Développement. Rationalité entrepreneuriat.

Resumen: El presente artículo analiza las acciones de responsabilidad socioambiental de Aracruz Celulose e Papel, reflexionando sobre los siguientes puntos: (1) si, genéricamente, ocurre una rearticulación del campo económico con bases en nuevos valores socioambientales que, a su vez, redimensionarían las instituciones del Estado, de la Sociedad y del Mercado; (2) si, más específicamente, en el nivel de interacción entre el ciudadano consumidor y el mercado son producidos efectos más sustentables. En profundidad, se discute las (in) congruencias entre lo global y lo local. Palabras clave: Responsabilidad socioambiental. Desarrollo. Racionalidad empresarial.
\end{abstract}

\section{Introdução}

A Aracruz Celulose e Papel é uma empresa capitalista que, primordialmente, deveria visar apenas ao lucro e, no entanto, dirige parte de seus recursos (de pessoal e financeiro) em ações que, em dado enquadramento institucional, poderiam ser identificadas como ações de Estado. Invariavelmente, cogita-se sobre o papel do Estado no Brasil no que concerne ao contexto dos desenvolvimentos vários (econômico, social e sustentável; local e regional); indaga-se sobre o papel efetivo do Estado para regular as ações de empresas e outros agentes no que se refere ao uso dos recursos naturais. O Estado continua a ser uma instituição fundamental para conceber e executar as políticas públicas requeridas para o desenvolvimento do país. Contudo apresenta-se, na realidade, um campo de

\footnotetext{
* Universidade Federal de Alagoas, Maceió, AL, Brasil

** Universidade Federal do Rio Grande do Sul, Porto Alegre, RS, Brasil.
} 
interação político, econômico e societário complexo que vige, senão às margens do Estado regulador, com certa autonomia dos instrumentos legais de regulação, conectando, no mercado e para além dele, as empresas e o cidadão-consumidor, gerando efeitos ainda não completamente dimensionados. O conjunto das ações de responsabilidade socioambiental da empresa Aracruz Celulose e Papel constituem uma indicação dessa realidade.

O fenômeno das ações de responsabilidade socioambiental das empresas, em geral, e da Aracruz, em particular, situa-se em meio a diversas abordagens que dissecam analiticamente as instituições políticas e econômicas, além das questões de desenvolvimento (local e global).

A interface entre as abordagens contemporâneas sobre as políticas desenvolvimentistas e a dos fenômenos e problemáticas ambientais que direta e indiretamente afetam as dinâmicas societárias, políticas e econômicas, parece prover uma rica visão dos mecanismos e dos processos que compõem um conjunto. Boa parte do esforço empreendido por pesquisadores por áreas de conhecimento, separa essas dinâmicas por meio de uma super especialização das disciplinas de conhecimento. Entretanto a conexão entre as partes é de suma importância quando se almeja entender a racionalidade de uma grande empresa como a Aracruz Celulose e Papel, no tocante ao redimensionamento e reorganização de seus planos de maneira que, a despeito da sua busca do lucro, ajusta-se a um ambiente com valores e práticas que denotam novos e/ou ressignificados valores que sustentam padrões de conduta.

Este artigo explora inicialmente os limites de atuação do Estado como formulador e gestor de políticas de desenvolvimento (econômico, social e ambiental) local e de maior escopo, incluindo seu papel regulador das ações econômicas das empresas no tocante às consequências ambientais de seus empreendimentos.

\section{Estado, empresas e meio ambiente}

Discutem-se, no Brasil, as novas formas de interação entre o Estado e o empresariado após as reformas econômicas de 1990 e as possibilidades de desenvolvimento que se descortinaram. Repensar os caminhos do desenvolvimento ganha novo vigor quando se verificam mudanças na ordem econômica internacional, da ascensão das economias periféricas, na década de 1980, do Sudeste Asiático, da Índia e da China, assim como do Brasil nos anos de 1990, na esteira do que se denominou de "países emergentes" e das discussões sobre o novo Estado desenvolvimentista.

Como contraponto às ideias liberais, Evans et al. (1985) ${ }^{1}$, na década de 1980, propuseram hipóteses sobre as novas conexões entre o Estado e a sociedade, afastando-se da noção do Estado como um problema e da solução liberal pelo seu insulamento da economia e da sociedade. Evans constrói uma tipologia de Estados que reforça a importância dos Estados desenvolvimentistas na condução da transformação industrial de um país. Em que pese às diferenças entre países em gradações de menos para mais eficácia com respeito a políticas e ações desenvolvimentistas, o que se vê é que Coreia do Sul, Japão, Taiwan, India, Brasil e demais países estudados apresentam disposições ativas, burocracias capacitadas, democracias deliberativas funcionais, capazes de promover o desenvolvimento econômico correspondente às suas peculiaridades institucionais. A abordagem institucionalista de Evans critica o receituário neoclássico que fundamentou o Consenso de Washington que, entre outras teses, defendia o afastamento do Estado da economia, a crença nas expectativas racionais e na universalidade das receitas econômicas ${ }^{2}$.

Ha-Joon Chang (2006) retorna a uma economia política do desenvolvimento - em decadência na década de 1970 pela sedução neoclássica -, ressaltando a importância das estruturas e das instituições econômicas e políticas nos países em desenvolvimento, notadamente do papel do Estado no âmbito do desenvolvimento econômico. O autor remedeia o silogismo neoclássico de que a esfera política é irreversível fator de distorção da

\footnotetext{
1 Vide Bringing The State Back In.

2 O receituário do Consenso de Washington foi mais bem empregado na América Latina do que em outras regiões do globo. Nos idos dos anos de 1980 estes países sofriam com desequilíbrios macroeconômicos, tendo encontrado, nos programas do Fundo Monetário Internacional e do Banco Mundial, plena acolhida.
} 
esfera do mercado (enunciado primeiro), daí, a necessidade da despolitização da economia (conclusão lógica). Chang reacende a controvérsia com a proposição de que o mercado é uma construção política, porque a sua lógica e as suas regras são parte do ambiente mais difuso da sociedade.

No âmbito da sociologia, as questões ambientais são redimensionadas com a Teoria da Modernização Ecológica (TME). Nos anos de 1980, concebia-se que os problemas ambientais podiam ser enfrentados por mecanismos e processos de industrialização baseados no desenvolvimento de tecnologias e com um mínimo de intervenção estatal. Os estímulos fundamentais para o melhoramento do ambiente relacionavam-se aos atores econômicos e empresariais ${ }^{3}$. Nesse contexto, destaque-se o conjunto de pesquisas capitaneadas por Arthur Mol (2002), que tomam a teoria da modernização ecológica como um exemplo de reflexividade institucional e da transformação da sociedade da alta modernidade, visível em setores produtivos como resposta às pressões ambientais e à crise ecológica. Nesse contexto, ora o Estado tem um papel relevante, ora tem um papel minimizado.

Brüseke (1996) assinala que o Relatório Brundtland (RB) apontava para uma compreensão entre causas e efeitos dos problemas socioeconômicos e ecológicos da sociedade global, porque relacionaria economia, tecnologia, sociedade e política. Ao Estado nacional, caberia (a) limitar o crescimento populacional; (b) preservar a biodiversidade e os ecossistemas, (c) diminuir o consumo de energia e desenvolver tecnologias que admitem o uso de fontes energéticas renováveis, (d) aumentar a produção industrial nos países não-industrializados na base de tecnologias ecologicamente adaptadas, etc. O RB foi duramente criticado ao estabelecer o preceito de consumo mínimo (necessidades básicas), omitindo-se sobre o que viria a ser o nível máximo de consumo (energia etc.).

A respeito da temática da regulação do Estado sobre o campo da realidade ambiental, Neder (1996) explora o problema da regulação

\footnotetext{
3 É destacado a passagem de um modelo centrado em indústrias de uso intensivo de recursos naturais e de energia para indústrias que minimizassem o consumo de recursos naturais e que fossem baseadas em serviços e conhecimento.
}

pública ambiental no Brasil, em meio à crise socioeconômica e à discussão sobre as opções para o desenvolvimento do país. Instituíramse, no país, mecanismos de centralização (federalização) e descentralização (órgãos locais, conselhos e instâncias de consultas e referendos) que dão efetividade à ação pública no tocante à preservação, à conservação e à gestão ambiental.

A hipótese do autor é que a ação pública não tem resolvido os problemas concretos de gestão ambiental no Brasil pela ausência de tratamento integrado das decisões macrossociais e macroeconômicas (emprego, renda, política industrial e urbana, pobreza e exclusão social), pelo predomínio de um setorialismo instituído na área ambiental, que tomou "como parâmetro de sua eficiência unicamente as ações internas a este campo comparativamente aos demais" (NEDER, 1996, p. 218). A abordagem adequada seria a análise integrativa entre as políticas setoriais circunvizinhas e os seus campos internos de articulação ${ }^{4}$. Além disso, as regulamentações públicas ambientais após a Constituição de 1988 tinham características conservacionistas (sem vinculação com as opções econômicoprodutivas), combinadas com traços de políticas de controle da poluição e de zoneamento industrial e com dispositivos para regularem decisões macroeconômicas. No início dos anos 1990, para financiar a Política Nacional de Meio Ambiente (PNMA), foi criado um Fundo Nacional do Meio Ambiente (FNMA) com recursos oriundos de organismos internacionais, além do orçamento público. Assim, organismos não-governamentais no país e no exterior (incluindo instituições financeiras internacionais) passaram a exigir cláusulas de restritividade ambiental em projetos de desenvolvimento de infraestrutura produtiva (energia e transportes) e social, urbana e regional, incluindo as áreas de saneamento e recursos hídricos.

Se, de um lado, as primeiras políticas públicas no Brasil tinham certa essência conservacionista, sob outro aspecto, o que se reconhece é uma postura governamental fragilizada com respeito a fazer com que a eco-

\footnotetext{
${ }^{4} \mathrm{O}$ autor vê as inadequações do setorialismo das políticas públicas ambientais no Brasil nas políticas de saneamento e de recursos hídricos.
} 
nomia brasileira se enquadrasse nos padrões de sustentabilidade. Viola (1998) analisou as políticas públicas do governo do presidente Fernando Henrique Cardoso (1994-2001) para a área ambiental e verificou que as "políticas ficaram isoladas dos centros de decisão econômica porque eram secundárias no que tange às prioridades das formulações governamentais relativamente ao desenvolvimento". Toda uma discussão mundial que apontava para uma nova economia com base no uso de tecnologias sustentáveis, no campo industrial e pós-industrial, ganhou um tratamento fragmentário e insuficiente. As demais políticas - reforma tributária, política energética e agrícola -, que faziam interface com a realidade socioambiental, padeceram dos mesmos males ${ }^{5}$.

Ferreira (2000) ressalta a perda de capacidade do Estado para responder aos desafios em um contexto de incertezas. A autora - considerando as ações pró-ativas dos movimentos sociais, empresários, sociedades científicas, sindicatos - indaga sobre se é imperativo atribuir somente ao Estado um papel preponderante na formulação, implantação e gerenciamento de políticas sustentáveis. A pesquisadora entende que a inanição do Estado não pode ser compreendida somente como gestão ineficiente, mas que se relaciona com o dado complexo de sua constituição, dos grupos que rivalizam entre si, como atores coletivos constituídos e não como um grupo monolítico. Haveria uma diversidade de policymakers dentro de um mesmo governo.

Todos os cenários, processos e ações conectadas à esfera do Estado no Brasil, no tocante aos assuntos socioambientais e, especificamente, centrados no funcionamento das instituições reguladoras do Estado, mostram que foram gerados resultados parciais e insuficientes, ora porque, no interior do próprio Estado, grupos diferentes disputavam projetos distintos e, muitas vezes, divergentes, ora porque o Estado, compartimentalizado, pro-

\footnotetext{
5 A reforma tributária não criou os incentivos para induzir a produção e consumo para níveis mais parcimoniosos; nem a cobrança de um imposto ambiental sobre os poluidores e os consumidores imprudentes. A política energética manteve-se focada na indústria do petróleo e indiferente às iniciativas ligadas a conservação da energia e o uso de energias renováveis.
}

duzia políticas setoriais que desconectavam diversas esferas da vida, a biofísica da esfera social, a econômica em relação à política.

À margem de um Estado com grandes dificuldades para gerir níveis e aspectos de realidade tão complexos, outras situações ganharam forma e substância. Para além dos mecanismos públicos de regulação, o cidadão-consumidor, tomado como uma agente inerte, sem poderes e cuja vontade moldava-se instantaneamente aos projetos e aos interesses das grandes empresas, demonstra novas disposições e valores em suas ações, a começar pelo consumo. As ações consumistas, além dos diagnósticos que destacaram a imprudência, refletem novas formas de ver o mundo com impacto direto sobre as grandes empresas.

É desse cenário competitivo para as empresas e as economias nacionais, em meio aos limites e às possibilidades de atuação do Estado no tocante à regulamentação econômica e ambiental no Brasil, que se deve tentar compreender as iniciativas de responsabilidade socioambiental ${ }^{6}$ da ARACRUZ Celulose e Papel. Verifica-se a adesão cada vez maior de grupos de empresas de diversos segmentos que, espontânea ou coercitivamente (por pressões de natureza legal ou advindas do próprio mercado), aderem aos programas e às ações de natureza "socioambiental". As empresas, para os fins últimos de obtenção de lucro, parecem adentrar, de forma mais visível e com certo desconforto, em uma arena política, porque se deparam com demandas que vêm de diversos segmentos da sociedade civil organizada relativamente aos motivos socioambientais. Essa esfera política apresenta interfaces intricadas, uma vez que envolve indivíduos e grupos situados em níveis local e global, que racionalizam com base em matrizes diversas de visões de mundo e que, ao final, necessariamente, não conformam um mundo socioeconômico e político perfeitamente balanceado e equilibrado. Assim sendo, as respostas das empresas, nesse

\footnotetext{
6 A noção de "socioambiental" não é pacífica nas discussões clássicas sobre sustentabilidade, porque a dimensão social não foi originariamente reconhecida como parte da realidade ambiental e ainda não o é de todo. Se do ponto de vista acadêmico a discussão é controversa, do ponto de vista das empresas trata-se de um conceito operacionalizado nas suas diversas rotinas.
} 
plano político, devidamente articuladas aos desafios competitivos que enfrentam no mercado, operacionalizam ações socioambientais pelas vantagens comparativas e relativas objetivas. Contudo não se trata de uma conduta estritamente estratégica da empresa no campo socioambiental, a despeito dos efeitos positivos na imagem das empresas.

As abordagens da teoria da maximização do lucro, como Friedmann (1970), postulam que preocupações dessa natureza, isto é, socioambiental, não deveriam ser objeto do interesse e dos esforços das empresas, porque constituiria papel precípuo do Estado e de outros organismos, de modo que as empresas deveriam focar-se somente na busca de maior rentabilidade e lucro para seus acionistas. De outra forma, ganha espaço a abordagem de que preocupações das empresas com variáveis sociais e ambientais, conectadas ao bem estar das comunidades circundantes e do cidadãoconsumidor, não podem ser estranhas à racionalidade empresarial ${ }^{7}$. Se, em um tempo, preocupações desse quilate podem significar custos adicionais que diminuem as margens de lucro e ameaçam a sobrevivência da empresa, em outros contextos de competitividade, as empresas precisam considerar essas variáveis na equação do seu negócio, ou podem perecer. O tempo perfeito em que dado contexto exige um padrão específico de resposta depende de uma estrutura à parte das empresas para se fazerem as prospecções correspondentes aos seus respectivos segmentos econômicos e as necessidades de ajustamento às demandas não econômicas (sociais, políticas).

Os desafios colocados às empresas no sentido de buscar padrões sustentáveis de produção e da necessidade de dialogar com a comunidade, a ponto de considerar efetivamente os valores desses indivíduos - impactam sobre seus processos de gestão e produção complexos, uma vez que as obrigam a criar uma estrutura paralela a sua atividadefim para realizar um conjunto de atividades voltadas a formas diversas de relacionamento com grupos humanos, com abordagens apropriadas para os projetos de interesses da comunidade e outros atores situados na arena socioambiental, identificados como stakeholders $^{8}$.

\footnotetext{
7 Vide Donaire (1994) e Epstein (1987).

${ }^{8}$ Freeman (1984) é quem inicialmente aborda a empresa
}

As empresas precisam responder com iniciativas no campo educacional e voltadas à minimização dos efeitos da pobreza e da desigualdade, para citar duas situações típicas. Daí que, via de regra, em face de uma visão pré-concebida da empresa como agente egoísta em um mundo egoísta (mercado), restalhes a visão final das ações socioambientais como peças de propaganda mais do que ação efetiva que denote comprometimento com o público. Postula-se que a realidade ganhou contornos menos marcados e que as relações e as instituições econômicas são constituídas socialmente a partir de novos elementos de valor que apontam para uma configuração peculiar, pelos valores evocados, no tempoespaço das esferas de produção e consumo contemporâneas, atormentadas pelos imperativos de uma ação econômica sustentável.

\section{Dinâmicas Sociais de produção da Responsabilidade Socioambiental das empresas}

Do ponto de vista das empresas, um dado coloca-se quase como um axioma: "Um dos efeitos da competição global foi o redirecionamento do poder para as mãos do comprador" (TACHIZAWA, 2007, p. 21). É no âmbito do comportamento dos consumidores que ocorre uma dinâmica que afeta a forma como a empresa organiza-se e relaciona-se com as outras, bem como os relacionamentos que estabelece com outras esferas da vida, não econômicas. O consumidor começa a considerar, além do preço e da qualidade dos produtos, o comportamento socioambiental das empresas fabricantes e prestadoras de serviços. O desdobramento do comportamento do consumidor é a criação, no universo da empresa, de novos conceitos de gestão que, progressivamente, atendam às demandas do referido consumidor. $\mathrm{O}$ comportamento ético das empresas passa a ser aferido por instituições públicas e privadas que, de forma independente, percorrem todo o ciclo de vida da empresa e do produto, conferindo-lhes certificados e certificações

como tendo responsabilidades que ultrapassam os interesses imediatos dos seus acionistas, para alcançar um conjunto mais amplo de grupos que são objetivamente afetados pelos empreendimentos da empresa. 
que têm credibilidade maior ou menor junto ao público. As empresas veem-se obrigadas a publicar o que se designa de Balanço Social e/ou Socioambiental - não somente com uma finalidade de gestão sobre os desempenhos econômico, social e ambiental -, mas como forma de dar publicidade a seus clientes, fornecedores e comunidade em geral ${ }^{9}$.

Sobre a credibilidade das instituições certificadoras, de seus instrumentos para perscrutar a realidade socioambiental que perpassa às ações das empresas, presume-se que essa temática ganhará ainda mais importância intelectual pela evidência da sua significação não somente para dimensionar aspectos ambientais, mas pelo valor político intrínseco que retém. Indivíduos e grupos com visões de mundo diversas, de classes sociais e localizadas por todos os continentes -, cada vez mais, consideram os resultados das diversas aferições indicativas da atenção dada pelas empresas às realidades (local e global).

Por isso o autor cita que, em pesquisa da Confederação Nacional da Indústria (CNI), $68 \%$ dos consumidores brasileiros estariam dispostos a pagar mais por um produto que não agredisse o meio ambiente. Outra pesquisa da CNI, consorciada com SEBRAE e BNDES, informa que $90 \%$ das grandes empresas e $35 \%$ das microempresas realizaram investimentos ambientais nos últimos anos para a adoção de práticas de gestão sob vários aspectos e níveis da realidade: “[não foram apenas em função da legislação, mas principalmente, [...], aumentar a competitividade das exportações; atender ao consumidor com preocupações ambientais; atender às reivindicações da comunidade; atender à pressão de organizações não governamentais e melhorar a imagem perante a sociedade" (TACHIZAWA, 2007, p. 24).

A racionalidade da empresa capitalista sempre esteve premida pelo aumento da produção e pela diminuição de custos, pesando os meios relativamente ao incremento de suas margens de lucro. Nesse tempo " $\mathrm{T}$ " zero ( $\mathrm{T}$ " 0 "), ou se otimizava o uso de mão de obra e dos insumos (destaque-se, recursos naturais), ou a sobrevivência no mercado estava sob risco e, dessa forma, estavam dados os ele-

9 Vide Carroll (1979), Cheibub (2002) e Demajorovic (2003). mentos para a consecução da maximização da utilidade. Esse tempo "zero" (" $\mathrm{T}$ " “ 0 ”), que bem pode, hipoteticamente, ser situado em um intervalo de tempo razoável (o início da modernidade capitalista), propunha consequências trágicas para os objetivos de um uso parcimonioso dos recursos naturais, porque não estavam operantes mecanismos regulatórios legais.

O papel regulador do Estado, a partir do século XIX, criaria os primeiros mecanismos atenuadores dos efeitos das ações econômicas predatórias sobre o meio ambiente e sobre dimensões sociais, como a pobreza. Nesse ponto, não se pode evocar a vigência instantânea, uniforme e completa que integrasse as dimensões difusas do social e do ambiental. Assim, para as empresas, no tempo " $\mathrm{T}$ " " 0 ", assumir posturas pró-ativas no que se refere aos impactos de suas atividades sobre o meio ambiente e sobre a sociedade produzia mais incertezas para a sua equação da maximização do lucro. No caso brasileiro, somente em meados da década de 1980, é que se verifica algum impacto da legislação ambiental, de fato, afetando a racionalidade das empresas. Um cenário simplificador parecia mostrar as bases em que se firmavam as primeiras iniciativas das empresas: em atenção à legislação vigente, as empresas ajustavam suas condutas de natureza mitigatória, sem maiores ganhos de imagem, ao mesmo tempo em que impunham um aumento de custos. Por este tempo, observa-se um aumento e eficácia da legislação e dos organismos estatais de controle, além da pressão política das ONG's, além do incremento, ainda que em pequena escala, dos temas ambientais na agenda política brasileira.

No tempo presente, isto é, ultrapassado o hipotético tempo " $\mathrm{T}$ " " 0 ", as empresas, de forma heterogênea, passam a medidas que, se não deixam de ter a natureza mitigatória, trazem a novidade de incorporar, nas práticas e nos processos produtivos, disposição mais pró-ativa, dirigidas a novos processos e produtos, otimizando o uso de energia e matéria prima e reciclagem de resíduos. Se, do ponto de vista dos custos, não acontece modificações maiores, do ponto de vista da imagem (de certo comprometimento com o meio ambiente) da empresa, os ganhos vêm pela visibilidade positiva. 
Desse modo, além das pressões legais, as empresas começam a mostrar-se preocupadas com as questões que afetam o cidadão comum na forma de certo voluntarismo ambiental corporativo. A palavra de ordem é antecipação aos problemas e, no que se refere à variável competitividade, o ambiente relativiza as vantagens naturais de obtenção de mão de obra mais barata. O diferencial "preocupação ambiental", traduzido em práticas corporativas, parece gerar efeitos em uma nova dinâmica de concorrência. A compreensão de todo o processo só se completa quando se verifica a pressão política externa ao funcionamento do mundo econômico, fundada em novos hábitos de consumo sugestionados por novos valores morais e de uma ética socioambiental capaz de afetar a racionalidade das empresas ${ }^{10}$. Velhas questões ganham novo enquadramento: as demandas sociais reprimidas na forma de menores salários são reembaladas como parte de iniciativas que denotam preocupação social das empresas. O diferencial competitivo, aqui, frise-se, gastos com proteção ambiental, deixam de ser vistos somente como custos para serem categorizados como investimentos e vantagem comparativa.

O centro decisório das empresas principia a operar considerando além dos atores/instituições convencionais dos fatores tradicionais como concorrentes, clientes, distribuidores e acionistas - a interface com os conteúdos de valor oriundos da sociedade civil. A diversidade e a complexidade das cadeias produtivas e as empresas de diversos setores absorvem, de forma heterogênea, as influências "não econômicas" sobre os seus respectivos negócios: se dependem de recursos naturais em abundância, se atuam em segmentos mais regulados por normas, se situados em ramos de alta competição por mão de obra qualificada, se mais ou menos suscetíveis às pressões do público consu-

\footnotetext{
${ }^{10}$ As bolsas de valores passaram a hierarquizar as empresas através de um índice de sustentabilidade. Estas empresas passaram a ser avaliadas como mais inovadoras, empreendedoras e como investimentos menos arriscados. O sistema financeiro internacional e nacional passou a gerir suas carteiras de financiamento considerandose as demandas e ações de responsabilidade socioambiental. É o caso do ABN AMRO Bank, Barclays, Citigroup, dentre outras instituições.
}

midor sugestionado por uma nova ética do consumo parcimonioso, etc. Desses condicionantes, pode-se estimar padrões diferentes de disposições relativamente às práticas corporativas de natureza socioambiental.

Para Tachizawa (2007), no tempo presente, tornam-se vantajosos para o marketing da empresa os apelos ecológicos dos produtos. Assim, 40 empresas (Tramontina; Tok \& Stock; Cickel entre outras) criaram um grupo de compradoras de Madeira Certificada com a adoção do selo de procedência da Forest Stewardship Council (FSC), que certifica ao consumidor florestas e produtos de madeira manejados corretamente do ponto de vista socioambiental.

Dessa forma, a gestão da empresa frente aos novos desafios competitivos no mercado torna-se uma questão relevante. Da atitude convencional defensiva e reativa frente aos problemas de passivos ambientais e tragédias sociais abundantes, as empresas ensaiam posturas mais ativas. Entre o simples estabelecimento de novas estratégias e a conversão profunda a novos valores ligados à sustentabilidade e à justiça social, objetivamente a empresa entra em uma nova arena de negócios com vieses políticos explícitos, em que precisa firmar parcerias e ouvir outras instâncias afetadas por seus negócios. Tachizawa (2007) denomina pensamento sistêmico o conjunto de conteúdos que está afetando profundamente as escolas formadoras de gestores e a cultura das empresas em geral. Nesse contexto, as posições intermediárias das empresas passam a ser objeto de questionamentos disseminados, mas eficientes:

Uma empresa pioneira pode ter um excelente programa de reciclagem e, ao mesmo tempo, pagar baixos salários, combater os sindicatos e não proporcionar benefícios de plano de saúde para os empregados e seus familiares. Uma empresa tradicional pode investir no trabalho revolucionário de pesquisa e de desenvolvimento de produtos ecologicamente inovadores e concluir que o custo relativo das multas, comparando com o custo da limpeza ambiental, justifica, a curto prazo, infringir as regulamentações da preservação ambiental. (TACHIZAWA, 2007, p. 29).

Para gerir o seu negócio nos novos tempos, as empresas buscam um perfil de gestor conhecido mais no ambiente acadêmico, 
isto é, de alguém com formação generalista e capaz de transitar em diversas áreas de conhecimento e de interagir em equipes multidisciplinares no interior da empresa e fora dela, na produção das novas respostas empresariais coerentes com o novo ambiente competitivo.

\section{O caso ARACRUZ Celulose e Papel (Fibria)}

A empresa Aracruz Celulose S.A. deixou de existir com esse nome em janeiro de 2009, quando ocorreu a fusão da empresa com a Votorantim Celulose e Papel (VCP), denominando-se Fibria ${ }^{11}$, e tornando-se a maior empresa mundial no ramo de celulose. É líder mundial na produção de celulose branqueada de eucalipto, produzindo $24 \%$ da oferta global do produto, sendo que $98 \%$ são exportados para Europa, América do Norte e Ásia, na forma de produtos como papéis para impressão e para escrever, papéis sanitários, lenços, guardanapos, entre outros produtos. Ressalve-se, neste ponto, que a pesquisa analisou os relatórios anuais de sustentabilidade dos anos de 2006, 2007 e 2008, antes da fusão com a VCP.

A sua produção provém de plantações de eucalipto que totalizam uma área de 313 mil hectares distribuídos pelos Estados do Espírito Santo, Bahia, Minas Gerais e Rio Grande do Sul. Além dos plantios próprios, a empresa conta com mais 96 mil hectares contratados a produtores independentes distribuídos nas mesmas regiões. A capacidade anual de produção da Aracruz era de 3,3 milhões de toneladas de celulose de fibra curta de eucalipto, realizada nas três unidades produtivas da empresa localizadas em Barra do Riacho (ES), Guaíba (RS) e Eunápolis (BA). A ARACRUZ figurou, até $2008^{12}$, no Índice Dow Jones de sustentabilidade (DJSI World) da bolsa de valores de Nova Iorque, porque se destacava entre as empresas mundiais com

\footnotetext{
${ }^{11} \mathrm{O}$ controle acionário da Fibria é exercido da seguinte forma: 35,8\% de ações no mercado, 34,9\% de ações do Banco Nacional de Desenvolvimento Social (BNDES) e 29,3\% de ações do grupo Votorantim (FIBRIA, 2009).

${ }^{12}$ Ano em que, em função da crise financeira mundial, a empresa realizou operações financeiras mal sucedidas com derivativos, acarretando grandes prejuízos para a mesma e por conta disto, sendo excluída do índice.
}

as melhores práticas em sustentabilidade corporativa, sendo a única no setor da celulose a figurar nesse índice. Todos os plantios da empresa são certificados pelo Sistema Brasileiro de Certificação Florestal (Cerflor), do Forest Stewardship Council (FSC). Entretanto a empresa tem sido contestada por conduta desabonadora no plano social por organizações nãogovernamentais (ONGs) e setores diversos da sociedade que a acusam de não distribuir os benefícios gerados. A empresa já respondeu judicialmente por ocupação de terra indígena e quilombola, de forma que todo esse quadro fez com que a empresa adotasse uma nova governança corporativa mais efetiva no campo socioambiental. Nesse sentido, o conflito com as populações indígenas foi resolvido com a assinatura de um termo de ajustamento de conduta pelas partes em 2007. Na esfera ambiental, a empresa é criticada pela poluição das águas e do ar, pela emissão de dioxinas na atmosfera, assim como pela manipulação de material cancerígeno na produção de celulose, afetando as condições de saúde das populações vizinhas as suas plantas industriais. Destaque-se a crítica disseminada antirreflorestamento de que o desenvolvimento do eucalipto exauriria os recursos hídricos e naturais do solo.

A Aracruz, por seu turno, introduziu algumas medidas preventivas direcionadas para (1) permitir a investigação sistemática dos programas de controle ambiental; (2) auxiliar na identificação de situações potenciais de problemas ambientais futuros; (3) verificar se a operação industrial está em conformidade com normas/padrões legais e também com padrões mais rigorosos definidos pela empresa.

A presente pesquisa trabalhou com níveis de análise construídos a partir dos relatórios de sustentabilidade da empresa, sublinhando uma discursividade reveladora de uma ordem de significados e representações informativas das práticas corporativas, nos âmbitos local e mundial, relativamente aos desafios nos mercados em que a Aracruz opera. Interessam, pois, as representações da empresa Aracruz Celulose com respeito a sua percepção da relação economia/sociedade, dos valores e motivações implicados. É, ademais, relevante captar a representação que a empresa faz de si mesma e do seu lugar 
no mundo corporativo e político no tempo presente.

A empresa afirmou não fazer distinção, no sentido de hierarquizar, entre os diversos atores institucionais com os quais se relaciona - clientes, consumidores, comunidades locais, governos etc. Ressalta, além disso, que o seu centro decisório só pode atuar em todas as direções com os mesmos elementos de valor: solidez, respeito, ética. Todavia a empresa sublinha a atenção maior que dirige para as instâncias dos consumidores, comunidades e ONG's, respectivamente, pela ressonância que a avaliação dessas instâncias gera na reputação da empresa. Em verdade, esta é a novidade: a Aracruz ampliou o campo sensível das preocupações socioambientais, grifem-se aquelas conectadas desde os motivos do cidadão-consumidor às comunidades afetadas pelos empreendimentos da empresa.

A Aracruz avalia como sendo delicado o relacionamento com as comunidades e com as partes interessadas diversas. Entende que essa ordem de realidade exige a construção de um cenário político do país. De outra sorte, depara-se com estados de carência das comunidades que, avalia, ultrapassam a função da empresa econômica, determinando que a empresa pondere até onde pode ir quanto ao estabelecimento de políticas nessa área. De forma genérica, a empresa, por meio de seus representantes, compreende que ações no sentido da mitigação da pobreza das comunidades podem redundar em maior segurança jurídica para as operações empresariais. Sobre o litígio com populações indígenas, a empresa ressente-se de um marco legal mais claro sobre a questão, assim sendo, não vê, em suas ações, o fator único para as tensões geradas. Ademais, a empresa avalia que o seu relacionamento com as partes interessadas pode melhorar se se fizer entender junto às comunidades. Dessa forma, investiu na reformulação do portal na Internet, visto como meio para fazer com que suas ações sejam mais efetivas no atendimento das demandas sociais das comunidades e para aperfeiçoar sua capacidade e método de dialogar com essas comunidades. Esse diagnóstico-solução tem, no modelo de racionalidade adotado pela empresa, a finalidade de reduzir a complexidade e a imprevisibilidade inerente a sua inserção nas comunidades afetadas. A
Aracruz, de outra forma, admite como um dos aprendizados que obteve no seu esforço por alcançar engajamento efetivo com as partes interessadas "a necessidade de treinamento do pessoal interno" para atuar nesse processo.

A Aracruz informa, em seus relatórios, investimentos sociais anuais de R\$ 16,8 milhões em 2006, R\$12,3 milhões em 2007 e de $\mathrm{R} \$ 19,5$ milhões em $2008^{13}$. O foco tem sido as carências das comunidades, especificamente com ações no campo educacional, capacitação profissional, saúde preventiva, segurança alimentar, arranjos produtivos locais, inclusão social, cultura, lazer e esportes, considerandose que os investimentos e as ações nesse campo necessitam de aperfeiçoamentos e ajustes. Em questão aqui, para o grupo empresarial, está o retorno para o capital simbólico da empresa, o que, conforme percebem, não está no nível esperado.

A empresa tem firmado relacionamento com as ONGs (vista como mais uma parte interessada), no contexto de diversos fóruns de organizações não governamentais tanto no Brasil, como no exterior. O histórico, nesse campo, guarda momentos de dificuldades e tensões, como se verifica no relatório de 2006, em que a empresa admite ter interrompido o diálogo com ONGs do Estado do Rio Grande do Sul após a invasão e a depredação de um dos seus hortos florestais no Estado. A ação foi promovida pelo movimento social Via Campesina, que a justificou como forma de defesa da biodiversidade da região ${ }^{14}$.

Sobre os seus fornecedores, a Aracruz adotou critérios para escolha, incluindo cláusulas contratuais que reforçassem o respeito às questões ambientais e sociais, com ênfase no total cumprimento da legislação trabalhis-

\footnotetext{
${ }^{13}$ Para fins de contextualização, traduzindo estes valores em dólares para uma cotação de 05.05.2011, quando os resultados da presente pesquisa estavam sendo consolidados, em que U\$ 1,00 dólar equivalia a R\$1,6 reais, chegava-se aos valores de U\$ $10.187,500$ milhões para o ano de 2006; U\$ 7.687.500,00 milhões em 2007 e U\$12.187.500,00 milhões para 2008. Isso sem considerar a inflação do período.

${ }^{14}$ A empresa também destaca sua participação no fórum internacional The Forests Dialogue (TFD), que é composto por ONGs ambientais e sociais, institutos de pesquisa, empresas florestais de diversas regiões do mundo e no World Business Council for Sustainable Development (WBCSD), onde participam instituições financeiras.
} 
ta, incluindo a proibição de qualquer forma de trabalho infantil ou escravo. A empresa, dentro da política de sustentabilidade social, também tem priorizado "a contratação de fornecedores locais, porque estimula a formação de uma cadeia de geração de valor que se estende às comunidades onde atua". Essa ação precisa ser coadunada com a procura de condições mais vantajosas para a empresa, como o baixo custo.

Sobre os mercados consumidores, até 2008 , o maior mercado era o europeu, conhecido pelas exigências socioambientais mais rigorosas, até ser ultrapassado pelo mercado norte-americano, menos exigente sob essa ótica. O mercado chinês cresce rapidamente e é ainda menos exigente quanto aos aspectos socioambientais. Assim posto, essa mudança de cenário levanta a questão sobre se a empresa mudará suas estratégias.

A empresa articula um elenco de razões que firmam suas estratégias visando à sustentabilidade de seu negócio. Têm ganhado proeminência as estratégias de ação voltadas para o estabelecimento de padrões socioambientais de apaziguamento com os stakenholders: comportamento ético da companhia em todos os níveis; consecução de uma solução final para a questão indígena; retomada do processo de certificação pelo FSC; avaliação dos impactos econômicos regionais das atividades da Aracruz; impactos dos plantios de eucalipto na biodiversidade; relacionamento com as comunidades descendentes de quilombolas; governança corporativa; impacto das plantações nas comunidades; relacionamento com comunidades indígenas; suprimento de madeira de terceiros. Esses tópicos, feitos prioridades, foram captados ouvindo-se o público externo (clientes, investidores e analistas financeiros, organizações não governamentais sociais e ambientais e fornecedores). Assim, verifica-se que a boa governança dos negócios tornou-se indissociável das ações voltadas ao público exterior diverso: comunidades circundantes e clientes, notadamente.

O empenho em atividades socioambientais mais claramente conecta-se à racionalidade do negócio, nos termos que segue: "As ações de responsabilidade socioambiental devem ser vistas como uma forma de investimento no sentido de buscar administrar riscos, desenvolver confiança e criar valor de forma sustentável"15. Em bases práticas, essas ações resultam em manutenção da "licença social para operar"; melhor acesso ao capital; manutenção do market share; redução de custos; motivação dos empregados; imagem e reputação.

A obtenção de certificações ambientais tem gerado efeitos eficientes nas práticas corporativas pelas exigências, na forma de um conjunto de normas e procedimentos que as entidades certificadoras exigem. Daí, que a decisão da empresa em submeter-se a um processo de certificação precisa ser entendida como parte de uma racionalização mais ampla em termos dos custos e dos benefícios. Talvez o mais palpável deles seja o acesso a novos mercados, principalmente, o mercado internacional, além da manutenção dos mercados atuais. Se se considera que uma interface técnico-política importante que subjaz aos parâmetros das certificadoras é a sincronia com os interesses e os valores de um público consumidor, tem-se que a variável "novos hábitos de consumo" não pode ser desprezada, mas tida como parte da equação complexa de mudança dos comportamentos individuais e coletivos que afetam os mercados. Os resultados financeiros da decisão da empresa em adotar políticas efetivas no campo socioambiental parecem ser amplamente compensadores: "O resultado dessa percepção positiva é, em parte, traduzido pelo fato de o mercado de capitais atribuir à Aracruz um valor (US\$ 6,3 bilhões) quase três vezes superior ao seu valor patrimonial".

\section{Algumas considerações à guisa de con- clusão}

No contraponto ao diagnóstico de Beck (1991) - sobre um cenário fatalista no que tange aos padrões de conduta das empresas, principalmente industriais e do primeiro mundo, que conjugava perda de controle do público (meios institucionais frágeis) para regular questões dessa natureza -, a reflexão sobre as políticas e as práticas de responsabilidade socioambiental de empresas apresenta novos e intrigantes elementos para se pensar a relação entre função econômica versus função ecológica.

\footnotetext{
$\overline{{ }^{15} \text { Vide ARACRUZ, } 2008, ~ p . ~} 6$.
} 
O estudo de caso da Aracruz Celulose e Papel indica tendências, sendo prematura a proposição de generalizações para o conjunto das empresas do setor e, quiçá, para a economia como um todo. Há um novo cenário econômico que só pode ser compreendido pelas injunções políticas e societárias de grande capilaridade. O mercado e as empresas, arrastados pelas máximas de diminuição de custos e aumento da lucratividade do negócio, têm que incorporar fatores, cenários e políticas efetivas em um campo novo, conectado a motivos não econômicos, no sentido de não ser a sua atividade específica. A novidade é o tipo humano do cidadão-consumidor eticamente motivado que, em grande escala, espalhado em campos diversos da economia, vem afetando, de forma heterogênea, a realidade dos mercados e das empresas.

A discussão do caso Aracruz recoloca, na agenda, o debate sobre elementos éticos que afetam o mundo econômico e podem indicar um novo equilíbrio na relação economia/meio ambiente. À parte disso, mas recuperada como questão importantíssima, está a dimensão social comprometida pelas atividades econômicas. Emerge, aqui, outro duplo que merece ser analisado, a saber, a relação entre esfera política e esfera econômica (mercado/empresas). Não é possível mais postular uma equação ecológica redutora que subestime a dimensão política da vida, no sentido de dispensável para se produzir os ajustes no âmbito da intervenção das empresas. O dado novo é que os resultados ambíguos de intervenção estatal de natureza coercitiva mostram-se menos eficazes do que aqueles gerados pela mudança de atitude política e pelo consumo por parte dos cidadãos consumidores.

As empresas reformulam seus projetos de maximização de utilidades incorporando o peso e o impacto da variável "cidadãoconsumidor", contudo as consequências disso, no sistema econômico-ecológico, ainda estão no plano do imponderável. É incontornável, porém, que se pense, como parte de uma mesma equação do agir econômico, os elementos de valor que denotam um agir com responsabilidade e comprometimento relativamente à sociedade e ao meio ambiente, com impactos nos planos local e global. Lado a lado, os ingredientes de uma cultura capita- lista egoísta e negativa precisam ser pensados à luz dos estímulos para um agir ético e de comprometimento verificados na figura do cidadão-consumidor em suas disposições cotidianas.

\section{Referências}

ARACRUZ Celulose. Relatório anual de sustentabilidade 2006, 2007, 2008. São Paulo. Disponível em: <http:// www.aracruzcelulose.com.br>. Acesso em: 8 set. 2009.

BECK, Ülrich. Risk Society: towards a new modernity. Londres: Sage, 1991.

BRÜSEKE, Franz. Desestruturação e desenvolvimento. In: FERREIRA, Leira da Costa; VIOLA, Eduardo (Orgs.). Incertezas de sustentabilidade na globalização. Campinas: UNICAMP, 1996. p. 103-132.

CARROLL, A. A three-dimensional conceptual model of corporate performance. Academy of Management Review, Mississipi, v. 4, p. 497-505, 1979.

CHANG, Ha-Joon. The east asian development experience: the miracle, the crisis and the future. London: Anthem Press, 2006.

CHEIBUB, Zairo; LOCKE, Richard. Valores ou interesses? Reflexões sobre a responsabilidade social das empresas. In: KIRSCHNER, Ana Maria; GOMES, Eduardo R.; CAPPELLIN, Paola (Orgs.). Empresa, empresários e globalização. Rio de Janeiro: Relume Dumará/ FAPERJ, 2002.

DEMAJOROVIC, Jacques. Sociedade de risco e responsabilidade socioambiental: perspectivas para a educação corporativa. São Paulo: Senac, 2003.

DONAIRE, Dennis. Considerações sobre a variável ambiental na empresa. Revista de administração de empresas, São Paulo, v. 34, n. 2, p. 68-77, 1994.

EPSTEIN, E. The corporate social policy process: beyond business ethics, corporate social responsability and corporate social responsiveness. California Management Review, v. 29, n. 3, p. 99-114, 1987.

EVANS, P.; RUESCHMEYER, D.; SKOCPOL, T. Bringing the state back in. Cambridge: Cambridge University Press, 1985.

FERREIRA, Leila da Costa. Ambiente E Sociedade, Campinas, SP, Ano III, n. 6/7, 1ํㅗㅇ sem. 2000/2º sem. 2000.

FIBRIA. Relatórios de Sustentabilidade. São Paulo, 2009. Disponível em: <http://www.fibria.com.br/rs2009/ shared/rs2009_pt.pdf>. Acesso em: 11 set. 2013.

FREEMAN, R. Strategic Management: a stakeholder approach. Boston: Pitman, 1984.

FRIEDMAN, M. The social responsability of business is to increase its profits. New York Times Magazine, v. 17, n. 6, p. 595-612, 1970.

MOL, A. P. J. Modernizacion ecológica: transformaciones industriales y reforma ambiental. In: REDCLIFT, Michael; WOODGATE, G. (Org.), Sociologia del medio ambiente: una perspectiva internacional. Madrid: Mcgraw-Hill/Interamericana de Espana, 2002. p. 143-156. 
NEDER, Ricardo T. O problema da regulação pública ambiental no Brasil: três casos. In: FERREIRA, Leira da Costa; VIOLA, Eduardo (Orgs.). Incertezas de sustentabilidade na globalização. Campinas, SP: UNICAMP. p. $217-240$.
TACHIZAWA, Takeshy. Gestão ambiental e responsabilidade social corporativa. Estratégias de negócios na realidade brasileira. São Paulo: Atlas, 2007.

VIOLA, Eduardo. Ambiente \& Sociedade, Campinas, SP, Ano II, n. 3, 2oㅗ. 1998 